\title{
Comparative genomic characterization of multidrug-resistant Citrobacter spp. strains in Fennec fox imported to China
}

Jie Qin ${ }^{1 \dagger}$, Yishu Zhao ${ }^{2,4 \dagger}$, Aifang Wang ${ }^{3,4}$, Xiaohui Chi ${ }^{4}$, Peipei Wen ${ }^{4}$, Shuang $\mathrm{Li}^{4}$, Lingjiao Wu ${ }^{4}$, Sheng Bi ${ }^{4}$ and $\mathrm{HaO} \mathrm{Xu}^{4^{*}}$ (1)

\begin{abstract}
Background: To investigate the antimicrobial profiles and genomic characteristics of MDR-Citrobacter spp. strains isolated from Fennec fox imported from Sudan to China.

Methods: Four Citrobacter spp. strains were isolated from stool samples. Individual fresh stool samples were collected and subsequently diluted in phosphate buffered saline as described previously. The diluted fecal samples were plated on MacConkey agar supplemented with $1 \mathrm{mg} / \mathrm{l}$ cefotaxime and incubated for $20 \mathrm{~h}$ at $37^{\circ} \mathrm{C}$. Matrix-assisted laser desorption/ionization-time of flight mass spectrometry (MALDI-TOF-MS) was used for identification. Antimicrobial susceptibility testing was performed using the broth microdilution method. Whole-genome sequencing was performed on an Illumina Novaseq-6000 platform. Acquired antimicrobial resistance genes and plasmid replicons were detected using ResFinder 4.1 and PlasmidFinder 1.3, respectively. Comparative genomic analysis of 277 Citrobacter genomes was also performed.
\end{abstract}

Results: Isolate FF141 was identified as Citrobacter cronae while isolate FF371, isolate FF414, and isolate FF423 were identified as Citrobacter braakii. Of these, three C. braakii isolates were further confirmed to be extended-spectrum $\beta$-lactamases (ESBL)-producer. All isolates are all multidrug resistance (MDR) with resistance to multiple antimicrobials. Plasmid of PKPC-CAV1321 belong to incompatibility (Inc) group. Comparative genomics analysis of Citrobacter isolates generated a large core-genome. Genetic diversity was observed in our bacterial collection, which clustered into five main clades. Human, environmental and animal Citrobacter isolates were distributed into five clusters.

Conclusions: To our knowledge, this is the first investigation of MDR-Citrobacter from Fennec Fox. Our phenotypic and genomic data further underscore the threat of increased ESBL prevalence in wild life and emphasize that increased effort should be committed to monitoring the potentially rapid dissemination of ESBL-producers with one health perspective.

Keywords: Citrobacter freundii, Fennec fox, Comparative genomic analysis, Bla $a_{\mathrm{CTX}-\mathrm{M}-13}$, anrS1

*Correspondence: xuhao0523@zju.edu.cn

${ }^{\dagger}$ Jie Qin and Yishu Zhao contributed equally to this work

${ }^{4}$ Collaborative Innovation Center for Diagnosis and Treatment of Infectious Diseases, State Key Laboratory for Diagnosis and Treatment of Infectious Diseases, The First Affiliated Hospital, School of Medicine, Zhejiang University, Hangzhou, China

Full list of author information is available at the end of the article

\section{Background}

The worldwide increase and spread of infections caused by multidrug-resistant (MDR) Gram-negative bacteria of human and animal origin is a significant global public health burden in recent decades [1, 2]. Enterobacteriaceae are common bacteria and usually associated with different types of community- and original author(s) and the source, provide a link to the Creative Commons licence, and indicate if changes were made. The images or other third party material in this article are included in the article's Creative Commons licence, unless indicated otherwise in a credit line to the material. If material is not included in the article's Creative Commons licence and your intended use is not permitted by statutory regulation or exceeds the permitted use, you will need to obtain permission directly from the copyright holder. To view a copy of this licence, visit http://creativecommons.org/licenses/by/4.0/. The Creative Commons Public Domain Dedication waiver (http://creativeco mmons.org/publicdomain/zero/1.0/) applies to the data made available in this article, unless otherwise stated in a credit line to the data. 
hospital-acquired infections and sometimes even animal infections [3-6]. Thus, antimicrobial resistance (AMR) in these bacteria has significantly potential impacts on the control of AMR from the perspective of the One Health concept $[7,8]$. Among these organisms, extended-spectrum $\beta$-lactamase (ESBL)-producing Enterobacteriaceae are recognized as the most prevalent group of pathogens due to their mobility $[9,10]$. Treatment of infections caused by ESBL- and AmpCproducing Enterobacteriaceae strains is challenging, due to the emergence and spread of carbapenem resistance in ESBL-producing Enterobacteriaceae isolates, which is of particular clinical relevance [11, 12].

The ESBLs are usually carried by mobile genetic elements, such as a variety of self-transferring plasmids, which can be transferred to other bacteria [13-15]. Thus far, several ESBL types have been identified in Enterobacteriaceae isolates of which the CTX-M, TEM, and SHV $\beta$-lactamases are the most prevalent groups $[16,17]$. It is noteworthy that ESBL- and carbapenemase-producing Enterobacteriaceae occurring in animals has become a public-health issue in recent years $[4,17]$. Zoonotic pathogens contributed to the crosstransmissions of ESBL-producing Enterobacteriaceae [18]. Previously, we also reported the detection of the transmission of AMR across human, animals and environmental compartments in China $[8,19,20]$.

Citrobacter spp. are common Gram-negative bacilli and widely found in water, food, soil, and intestines of animals and humans [21]. AMR encoding genes are frequently reported in Citrobacter freundii, and it became a reservoir of antibiotic resistance genes in recent years [22, 23]. In addition, MDR $C$. freundii has been reported in numerous hosts including but are not limited to humans [24-26]. In this work, we identified four MDR Citrobacter isolates in Fennec fox imported from Sudan to China. Antimicrobial susceptibility tests, conjugation experiments, whole-genome sequencing, and comparative genomic analysis were performed to study the molecular characteristics of these MDR strains.

\section{Results}

\section{Isolation and identification}

In this work, four Citrobacter spp. isolates resistant to cephalosporins were cultivated by selective medium plates. Among these strains, isolate FF141 was identified as Citrobacter cronae while isolate FF371, isolate FF414, and isolate FF423 were identified as Citrobacter braakii (Additional file 1: Figure S1). Of these, three $C$. braakii isolates were further confirmed to be ESBL-producer (Table 1).

\section{Assessment of antibiotic susceptibility and MLST analysis}

Four Citrobacter isolates are all MDR with resistance to multiple antimicrobials (Table 1 ). The total resistance rate was observed for cefotaxime, ceftazidime, aztreonam, and chloramphenicol (100\%). All the isolates were susceptible to imipenem, meropenem, amikacin, tigecycline, and colistin. Interestingly, only FF371 was resistant to piperacillin-tazobactam. Among these Citrobacter isolates, we found two sequence types (STs), which were ST350 (FF371, FF414, and FF423) and ST370 (FF141).

\section{Resistant and virulence determinants of Citrobacter isolates}

The acquired resistance genes detected in four Citrobacter isolates are summarized in Fig. 1A. The following genes were identified in three $C$. braakii isolates: the phenicol resistance gene floR; the trimethoprim resistance gene dfrA17; the tetracycline resistance gene $\operatorname{tet}(A)$; the disinfectant resistance gene $q a e E$; the quinolone resistance gene qurS1; the fluoroquinolone and aminoglycoside resistance gene $a a c\left(6^{\prime}\right)-I b-c r$, the aminoglycoside resistance genes $a p h(6)-I d, a a c\left(6^{\prime}\right)-I b 3, a p h\left(3^{\prime \prime}\right)-I b$, $a a c(3)$ IId, and aadA5; the macrolide resistance gene $m p h(A)$; the $\beta$-lactam resistance genes $b l a_{\mathrm{CTX}-\mathrm{M}-55}, \quad b l a_{\mathrm{CMY}-82}$, and $b l a_{\text {OXA-1 }}$; the rifampicin resistance gene $A R R-3$; sulphonamide resistance genes sul1, and sul2. Of note, $C$. braakii FF414 and FF423 encoded the fosfomycin resistance gene fos $A 3$, while $C$. cronae FF141 and C. braakii FF371 were negative. Among four isolates, FF141 encoded fewer resistance genes than other isolates, which carried

Table 1 The minimum inhibitory concentration (MIC) of four Citrobacter spp. isolates

\begin{tabular}{|c|c|c|c|c|c|c|c|c|c|c|c|c|c|c|c|c|}
\hline Isolate & TZP & CTX & CAZ & CPO & IPM & MEM & AMK & ATM & CIP & $\mathrm{CHL}$ & FLR & GEN & TOB & FOS & TGC & $\mathrm{COL}$ \\
\hline FF141 & 64 & 32 & 64 & 1 & 0.25 & 0.0075 & 8 & 64 & 0.25 & 64 & 16 & 4 & 1 & 0.25 & 0.25 & 2 \\
\hline FF371 & 128 & $>128$ & 64 & 128 & 0.25 & 0.003 & 32 & 128 & 16 & 128 & 128 & $>128$ & 64 & 256 & 0.25 & 2 \\
\hline FF414 & 2 & $>128$ & 64 & 128 & 0.25 & 0.003 & 16 & 128 & 16 & 128 & 128 & $>128$ & 64 & 256 & 0.25 & 2 \\
\hline FF423 & 2 & $>128$ & 64 & $>128$ & 0.25 & 0.003 & 16 & 128 & 16 & 128 & $>128$ & $>128$ & 64 & 256 & 0.25 & 2 \\
\hline
\end{tabular}

Concentration unit: $\mu \mathrm{g} / \mathrm{ml}$

TZP Piperacillin/tazobactam, CTX cefotaxime, CAZ ceftazidime, CPO cefpirome, IMP Imipenem, MEM meropenem, AMK amikacin, ATM aztreonam, CIP ciprofloxacin, CHL chloramphenicol, FLR florfenicol, GEN gentamicin, TOB tobramycin, FOS fosfomycin, TGC tigecycline, COL colistin 


\section{A}

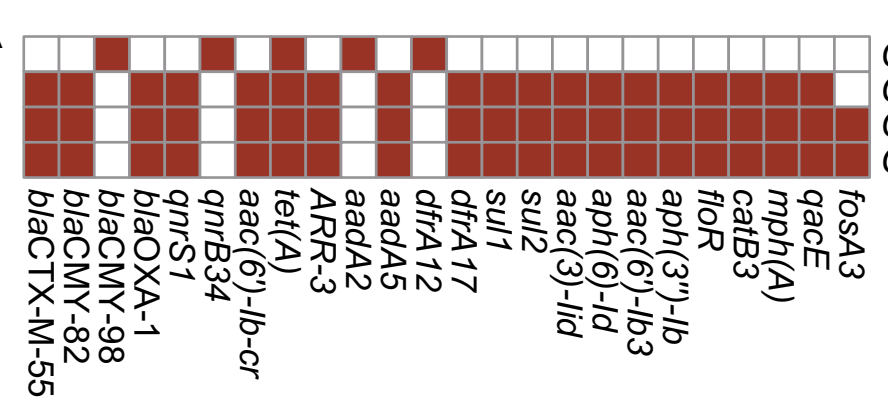

Citrobacter cronae FF141

Citrobacter braakii FF371

Citrobacter braakii FF414

Positive

Citrobacter braakii FF423

Negative

B
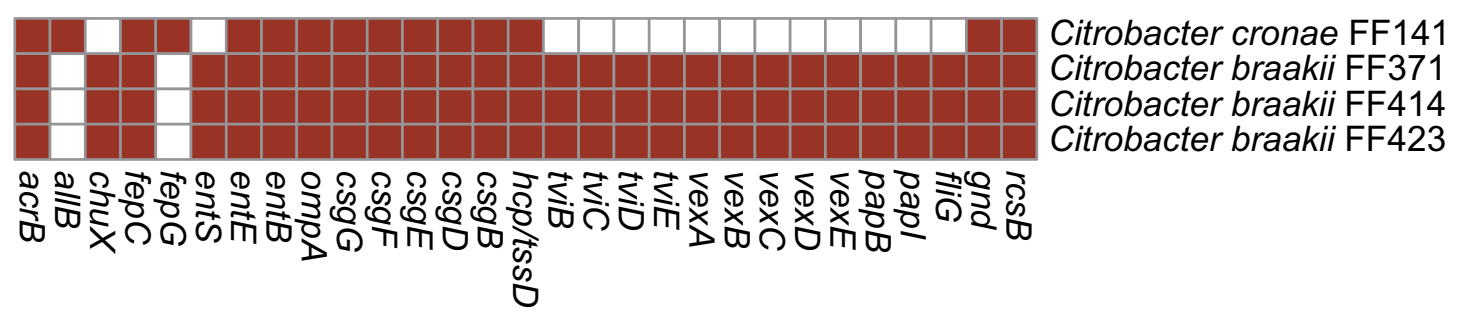

Fig. 1 A Antimicrobial resistance gene profiles of 4 MDR-Citrobacter isolates. The heatmap is used to display the types of acquired AMR genes. Brown indicates the presence of AMR genes, whereas colorless correspond to the absence of the AMR genes. B The heatmap is used to display the types of virulence-associated genes. Brown indicates the presence of virulence genes, whereas colorless correspond to the absence of the virulence genes

bla $_{\mathrm{CMY}-98}$, qnrB34, tet(A), dfrA12, and aadA2. Plasmids of incompatibility (Inc) group pKPC-CAV1321, was identified in FF141, and IncR was detected in other Citrobacter braakii isolates (Additional file 2: Table S1). The antimicrobial genes $\operatorname{dfr} A 12$, tet $(A)$, and $\operatorname{aadA2}$ genes were coharbored by IncR plasmid in three $C$. braakii isolates.

Virulence gene analysis showed that the presence of genes encoding efflux pump protein $(\operatorname{arc} B)$, the transport of siderophores $(f e p C)$, enterobactin (entB and entE), outer membrane protein A (ompA), extracellular nucleation factors $(\operatorname{csg} B, \operatorname{csg} D, \operatorname{csg} E$, and $\operatorname{csg} F)$, and type VI secretion system-related proteins $(h c p / t s s D)$ in all isolates (Fig. 1B). Moreover, three C. braakii isolates also carried genes that involved polymer synthesis $(t v i B-t v i E)$, and cell surface localization of the CPS (vexA-vexE).

\section{Comparative genomics analysis of Citrobacter isolates}

Roary matrix-based gene sequence analysis generated 60,923 total genes and a large core-genome of 1578 gene clusters of 277 whole genomes. The whole-genome phylogeny (Fig. 2) revealed a population structure. Genetic diversity was observed in our bacterial collection, which clustered into five main clades. Interestingly, C. braakii isolates have close relatedness with a clinical isolate (SAMD00112928, C. freundii) from Vietnam and an environmental strain (SAMN11928073, C. freundii), while C. cronae FF141 showed a high similarity with a clinical isolate from Nigeria (SAMN13830004, C. freundii) and a clinical isolate from India (SAMN06660612, C. freundii) (Fig. 2, Additional file 3: Table S2).

\section{Discussion}

The wide dissemination of MDR Enterobacteriaceae is a global concern with one health perspective [27]. In clinical settings, Citrobacter spp. isolates represent up to $6 \%$ of all isolated Enterobacteriaceae from clinical specimens [28]. Members of the genus Citrobacter are reported to associate with nosocomial infections for a high mortality rate [29]. The Citrobacter genus is most closely related to Escherichia coli and Salmonella, and is divided into 11 different genomospecies [30]. There is some information indicating a high prevalence of MDR Enterobacteriaceae in wild animals [31, 32]. Although previous studies suggest that fur animals are potential reservoirs of AMR [5, 33], little is known about the antimicrobial patterns, and genomic characteristics of MDR Citrobacter isolates from wildlife. In the present study, we first described the isolation of MDR-Citrobacter strains from Fennec fox. We subsequently obtained the antimicrobial resistance profiles and genomic information by AST and WGS. We also identified antimicrobial resistance and virulence-associated genes.

Citrobacter spp. isolates can have chromosomal AmpC $\beta$-lactamases, as well as plasmid encoded carbapenemases, which results in ineffective of many antimicrobial agents for treatment $[20,22,34,35]$. C. cronae was 


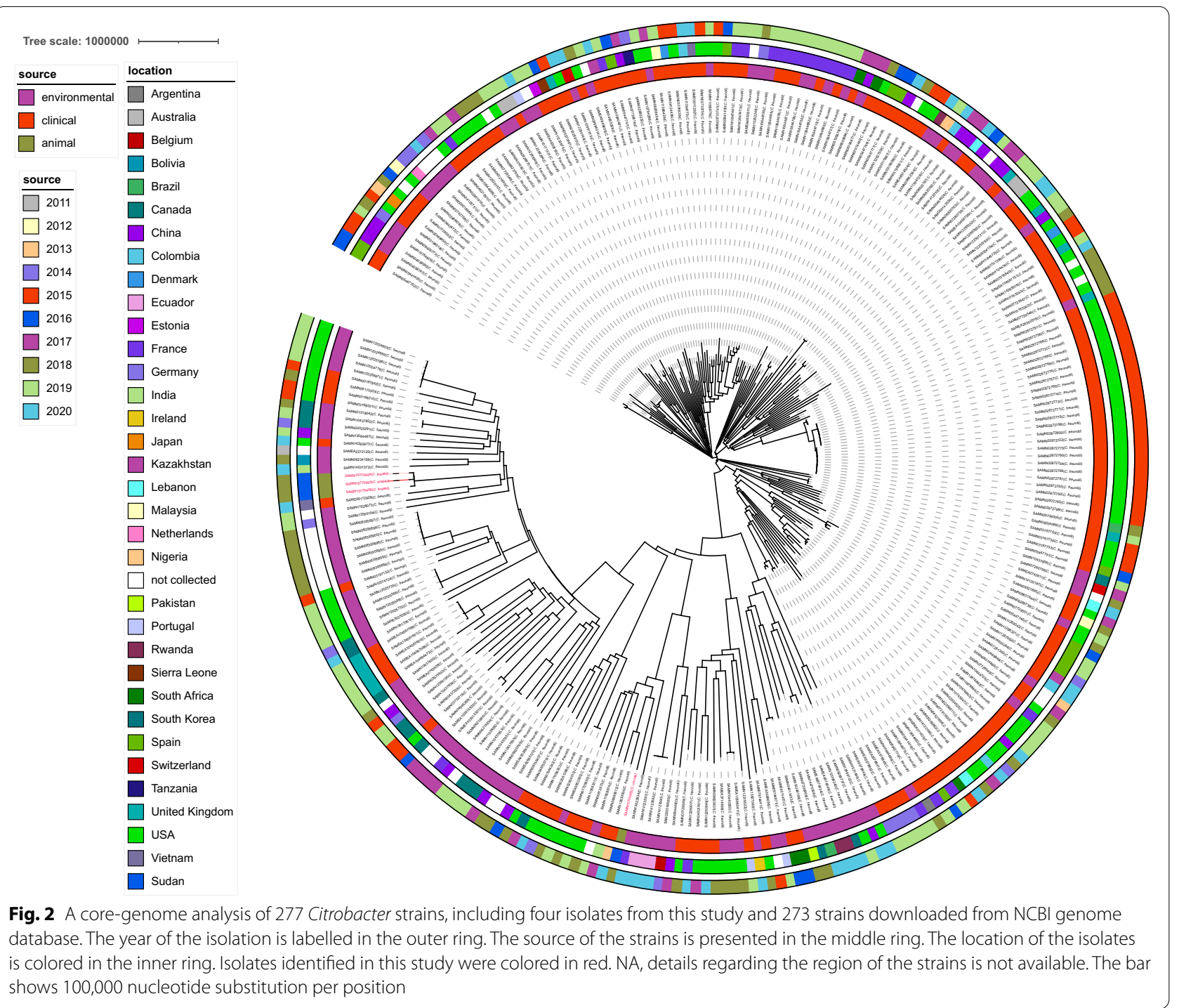

identified as a new Citrobacter species from human stool samples very recently [28], the antimicrobial profiles of C. cronae are largely unknow. In this study, we first identified an AmpC $\beta$-lactamase encoding gene $\left(b l a_{\mathrm{CMY}-98}\right)$ in C. cronae, which provides a glimpse of antimicrobial insight into this species. Occurrence of ESBL-producing C. braakii isolated from animals and food product are occasionally reported [36]. Our detection of three ESBLproducing C. braakii isolates from Fennec fox further suggests the risk of zoonotic potential MDR C. braakii from animals and animal products deservedly garners considerable attention.

Previous investigations found that CTX-M-55 became one of the prevalent ESBL type detected among clinical, animals, and environment in some countries [13, 14, 37, 38]. Very recently, the occurrences of
CTX-M-55-producing Escherichia coli were also increasingly reported in environment and diverse animal species in Europe [39, 40]. Our previous work confirmed that CTX-M-55-producing Escherichia coli was the most prevalent ESBL-producer from Fennec fox [5]. These findings further strengthened that wildlife may act as potential reservoirs and vectors of CTX-M-55, although some of these isolates carried $b l a_{\text {CTX-M-55 }}$ genes on the chromosome.

Interestingly, the diverging clonality of the human, environmental and animal Citrobacter isolates was confirmed by the fact that strains originating in these three sources distributed into five clusters. It is still not sure whether the ecological and animal strains are highly related to the human strains in terms of genetic phylogeny. The previous investigation highlighted the challenges 
associated with species designation of Citrobacter by core genome analysis, particularly in regards to Citrobacter freundii, which did not constitute a discrete phylogenetic group [41]. As we noted in our data, C. cronae and $C$. braakii strains were clustered into the same clade, which suggests further accurate taxonomic inquiry is needed to clarify the lineage of Citrobacter members.

\section{Conclusion}

In summary, this investigation involved the first survey of MDR Citrobacter isolates in Fennec fox. We characterized the phenotypic characteristics and genomic basis of MDR Citrobacter strains. Fennec fox may serve as a common vector for the rapid dissemination of ESBLencoding genes via animal contact and thereby threaten public health. Our findings further underscore the threat of increased ESBL prevalence in Enterobacteriaceae, and improved multisectoral surveillance for ESBL-producing Citrobacter is warranted.

\section{Methods and materials}

Bacterial identification and isolation of Citrobacter strains We collected 168 stool samples of wild Fennec fox imported from North Africa to China [5]. Stool samples were cultured by MacConkey agar supplemented with $1 \mathrm{mg} / \mathrm{l}$ cefotaxime as described previously [5]. Bacterial identification was conducted by MALDI-TOF MS (Bruker, Bremen, Germany) as described [15]. Confirmation of ESBL-producing isolations was further performed by a standard double-disk diffusion method as defined by the Clinical and Laboratory Standards Institute (CLSI) (https://clsi.org/).

\section{Antimicrobial susceptibility testing (AST)}

Susceptibility to 16 antibiotics (amikacin, aztreonam, cefpirome, cefotaxime, ceftazidime, chloramphenicol, ciprofloxacin, florfenicol, fosfomycin, gentamicin, imipenem, meropenem, piperacillin-tazobactam, polymyxin E, tigecycline, tobramycin, and trimethoprim-sulfamethoxazole) for four MDR Citrobacter isolates were evaluated. The MICs were determined via an agar dilution method for all antibiotics except for colistin and tigecycline, for which a broth microdilution method was used according to the CLSI standards. E. coli ATCC 25922 was used as control.

\section{Whole-genome sequencing (WGS) and bioinformatics analysis}

Genomic DNA was extracted from four MDR Citrobacter isolates using the Qiagen Blood/Tissue kit (Qiagen, Hilden, Germany) [6]. The sequencing library was prepared by using Illumina Nextera XT kit (Illumina, San Diego, CA, USA) and sequenced using the Illumina
NovaSeq 6000-PE150 platform (Illumina). Paired reads were then assembled into scaffolds using Velvet version 1.2.10 [42]. Acquired antimicrobial resistance genes and plasmid replicons were performed using the CGE server (http://www.genomicepidemiology.org). Antibiotics Resistance Genes (ARGs) were identified using the ResFinder 4.1 database [43]. Genotyping was performed to query the seven domesticated genes (aspC, $c l p X, f a d D$, $m d h$, arcA, dnaG, and lysP) via the MLST database (https://pubmlst.org/organisms/citrobacter-spp). We further created a core genome-based phylogenetic tree using 4 Citrobacter genomes sequenced in this study and 272 randomly selected publicly available Citrobacter genomes (Additional file 1: Table S1). The isolate collection includes strains from clinical $(n=159)$ and the environment $(n=133)$ sources that were widely distributed over time and geographical locations. Citrobacter genomes were annotated using Prokka [44] and RAST tool [45]. The core genes were identified using Prokka [44] and maximum likelihood-based phylogenetic reconstruction was performed with Roary [46]. Phylogenetic tree visualizations were generated by using iTOL (https:// itol.embl.de/).

\section{Plasmid characterization}

The transferability of plasmids carrying MDR encoding genes was determined by filter mating as described previously [19]. Animal isolates and Escherichia coli J53 were used as donors and acceptors, respectively. The animal isolates and J53 strains were mixed in (LB) broth at a ratio of $1: 3$ and incubated at $37^{\circ} \mathrm{C}$ for $18 \mathrm{~h}$. Transduction and binding were selected on MacConkey agar plates containing cefotaxime $(2 \mu \mathrm{g} / \mathrm{ml})$ and sodium azide $(150 \mu \mathrm{g} /$ $\mathrm{ml}$ ) for $12 \mathrm{~h}$. Susceptibility test was performed to determine the horizontal transferability of drug resistance, and the corresponding transduction conjugate was confirmed by PCR amplification and pulsed field gel electrophoresis (PFGE) (Additional file 2: Table S2).

\section{Supplementary Information}

The online version contains supplementary material available at https://doi. org/10.1186/s13099-021-00458-w.

Additional file 1: Figure S1. MS fingerprinting spectrum for each of the four identified Citrobacter strains result of Matrix-assisted laser desorption/ ionization-time of flight mass spectrometry (MALDI-TOF-MS).

Additional file 2: Table S1. List of information for the four genomes that were sequenced in this study.

Additional file 3: Table S2. List of strains and genome sequences that were used in this study.

Acknowledgements Not applicable. 


\section{Authors' contributions}

Conceptualization, JQ; methodology, YZ; software, $X C$; validation, JQ, YZ; formal analysis, $X C$; investigation, $A W$; resources, $P W$; data curation, SL; writing original draft preparation, $\mathrm{HX}$; writing-review and editing, $\mathrm{SB}$; visualization, $\mathrm{HX}$; supervision, LW; project administration, HX; funding acquisition, SB. All authors read and approved the final manuscript.

\section{Funding}

This work was supported by the National Key Research and Development Program of China (No. 2016YFD0501105) and the National Natural Science Foundation of China (No. 82072314).

\section{Data availability}

The whole-genome sequences of four Citrobacter spp. isolates have been deposited in the GenBank under the BioProject number PRJNA656097.

\section{Declarations}

Ethics approval and consent to participate

Not required.

\section{Consent for publication}

Yes.

\section{Competing interests}

The authors declare that they have no competing interests.

\section{Author details}

${ }^{1}$ Emergency Department of Taizhou Hospital, Taizhou, China. ${ }^{2}$ Department of Rheumatology and Immunology, Shandong Provincial Hospital, Jinan, China. ${ }^{3}$ Department of Laboratory Medicine, Zhucheng People's Hospital, Zhucheng, China. ${ }^{4}$ Collaborative Innovation Center for Diagnosis and Treatment of Infectious Diseases, State Key Laboratory for Diagnosis and Treatment of Infectious Diseases, The First Affiliated Hospital, School of Medicine, Zhejiang University, Hangzhou, China.

\section{Received: 21 May 2021 Accepted: 6 October 2021}

Published online: 13 October 2021

\section{References}

1. Kern WV, Rieg S. Burden of bacterial bloodstream infection-a brief update on epidemiology and significance of multidrug-resistant pathogens. Clin Microbiol Infect. 2020;26(2):151-7.

2. Giacobbe DR, Ciacco E, Girmenia C, Pea F, Rossolini GM, Sotgiu G, Tascini C, Tumbarello M, Viale P, Bassetti M, et al. Evaluating cefiderocol in the treatment of multidrug-resistant gram-negative bacilli: a review of the emerging data. Infect Drug Resist. 2020;13:4697-711.

3. Mahamat OO, Kempf M, Lounnas M, Tidjani A, Hide M, Benavides JA, Carriere $\mathrm{C}$, Banuls AL, Jean-Pierre H, Ouedraogo AS, et al. Epidemiology and prevalence of extended-spectrum beta-lactamase- and carbapenemaseproducing Enterobacteriaceae in humans, animals and the environment in West and Central Africa. Int J Antimicrob Agents. 2021;57(1):106203.

4. Madec JY, Haenni M, Nordmann P, Poirel L. Extended-spectrum betalactamase/AmpC- and carbapenemase-producing Enterobacteriaceae in animals: a threat for humans? Clin Microbiol Infect. 2017:23(11):826-33.

5. Feng C, Wen P, Xu H, Chi X, Li S, Yu X, Lin X, Wu S, Zheng B. Emergence and comparative genomics analysis of extended-spectrum-beta-lactamase-producing Escherichia coli carrying mcr-1 in Fennec Fox Imported from Sudan to China. mSphere. 2019;4(6):e00732-19.

6. Zheng B, Xu H, Lv T, Guo L, Xiao Y, Huang C, Zhang S, Chen Y, Han H, Shen $P$, et al. Stool samples of acute diarrhea inpatients as a reservoir of ST11 hypervirulent KPC-2-producing Klebsiella pneumoniae. mSystems. 2020;5(3):e00498-20.

7. Cars O, Xiao Y, Stalsby Lundborg C, Nilsson LE, Shen J, Sun Q, Bi Z, Borjesson S, Greko C, Wang Y, et al. Building bridges to operationalise one health-a Sino-Swedish collaboration to tackle antibiotic resistance. One Health. 2016;2:139-43.
8. Zheng B, Xu H, Huang C, Yu X, Guo L, Han H, Zhang J, Jiang X, Chen C, Xiao Y. Occurrence and genomic characterization of two MCR-1-producing Escherichia coli isolates from the Same Mink Farmer. mSphere. 2019;4(6):e00602-19.

9. Tzouvelekis LS, Markogiannakis A, Psichogiou M, Tassios PT, Daikos GL. Carbapenemases in Klebsiella pneumoniae and other Enterobacteriaceae: an evolving crisis of global dimensions. Clin Microbiol Rev. 2012;25(4):682-707.

10. Rojas LJ, Salim M, Cober E, Richter SS, Perez F, Salata RA, Kalayjian RC, Watkins RR, Marshall S, Rudin SD, et al. Colistin resistance in carbapenemresistant Klebsiella pneumoniae: laboratory detection and impact on mortality. Clin Infect Dis. 2017;64(6):711-8.

11. Nordmann P, Cuzon G, Naas T. The real threat of Klebsiella pneumoniae carbapenemase-producing bacteria. Lancet Infect Dis. 2009;9(4):228-36.

12. Grundmann H, Glasner C, Albiger B, Aanensen DM, Tomlinson CT, Andrasevic AT, Canton R, Carmeli Y, Friedrich AW, Giske CG, et al. Occurrence of carbapenemase-producing Klebsiella pneumoniae and Escherichia coli in the European survey of carbapenemase-producing Enterobacteriaceae (EUSCAPE): a prospective, multinational study. Lancet Infect Dis. 2017:17(2):153-63.

13. Zhang J, Zhou K, Zheng B, Zhao L, Shen P, Ji J, Wei Z, Li L, Zhou J, Xiao Y. High prevalence of ESBL-producing Klebsiella pneumoniae causing community-onset infections in China. Front Microbiol. 2016;7:1830.

14. Zhang J, Zheng B, Zhao L, Wei Z, Ji J, Li L, Xiao Y. Nationwide high prevalence of CTX-M and an increase of CTX-M-55 in Escherichia coli isolated from patients with community-onset infections in Chinese county hospitals. BMC Infect Dis. 2014;14:659.

15. Zheng B, Feng C, Xu H, Yu X, Guo L, Jiang X, Song X. Detection and characterization of ESBL-producing Escherichia coli expressing mcr-1 from dairy cows in China. J Antimicrob Chemother. 2019;74(2):321-5.

16. Bush K, Bradford PA. Epidemiology of beta-lactamase-producing pathogens. Clin Microbiol Rev. 2020;33(2):e00047-19.

17. Bevan ER, Jones AM, Hawkey PM. Global epidemiology of CTX-M betalactamases: temporal and geographical shifts in genotype. J Antimicrob Chemother. 2017:72(8):2145-55.

18. Katale BZ, Misinzo G, Mshana SE, Chiyangi H, Campino S, Clark TG, Good L, Rweyemamu MM, Matee MI. Genetic diversity and risk factors for the transmission of antimicrobial resistance across human, animals and environmental compartments in East Africa: a review. Antimicrob Resist Infect Control. 2020;9(1):127.

19. Zheng B, Huang C, Xu H, Guo L, Zhang J, Wang X, Jiang X, Yu X, Jin L, Li X, et al. Occurrence and genomic characterization of ESBL-producing, MCR1-harboring Escherichia coli in farming soil. Front Microbiol. 2017;8:2510.

20. Xu H, Wang X, Yu X, Zhang J, Guo L, Huang C, Jiang X, Li X, Feng Y, Zheng B. First detection and genomics analysis of KPC-2-producing Citrobacter isolates from river sediments. Environ Pollut. 2018:235:931-7.

21. Liu LH, Wang NY, Wu AY, Lin CC, Lee CM, Liu CP. Citrobacter freundii bacteremia: risk factors of mortality and prevalence of resistance genes. $J$ Microbiol Immunol Infect. 2018;51(4):565-72.

22. Chi X, Guo J, Zhou Y, Xiao T, Xu H, Lv T, Chen C, Chen J, Zheng B. Complete-genome sequencing and comparative genomic characterization of an IMP-4 producing Citrobacter freundii isolate from patient with diarrhea. Infect Drug Resist. 2020;13:1057-65.

23. Jiang $X$, Cui X, Liu W, Xu H, Zheng B. Genetic characterization of a novel sequence type of multidrug-resistant Citrobacter freundii strain recovered from wastewater treatment plant. Infect Drug Resist. 2019;12:2775-9.

24. Sadek M, Ortiz de la Rosa JM, Abdelfattah Maky M, Korashe Dandrawy M, Nordmann P, Poirel L. Genomic features of MCR-1 and extended-spectrum beta-lactamase-producing enterobacterales from retail raw chicken in Egypt. Microorganisms. 2021;9(1):195.

25. Shnaiderman-Torban A, Steinman A, Meidan G, Paitan Y, Abu Ahmad W, Navon-Venezia S. Petting zoo animals as an emerging reservoir of extended-spectrum beta-lactamase and AmpC-producing enterobacteriaceae. Front Microbiol. 2019:10:2488.

26. Goldberg DW, Fernandes MR, Sellera FP, Costa DGC, Loureiro Bracarense AP, Lincopan N. Genetic background of CTX-M-15-producing Enterobacter hormaechei ST114 and Citrobacter freundii ST265 co-infecting a free-living green turtle (Chelonia mydas). Zoonoses Public Health. 2019:66(5):540-5. 
27. Booton RD, Meeyai A, Alhusein N, Buller H, Feil E, Lambert H, Mongkolsuk S, Pitchforth E, Reyher KK, Sakcamduang W, et al. One Health drivers of antibacterial resistance: quantifying the relative impacts of human, animal and environmental use and transmission. One Health. 2021;12:100220

28. Oberhettinger P, Schule L, Marschal M, Bezdan D, Ossowski S, Dorfel D, Vogel W, Rossen JW, Willmann M, Peter S. Description of Citrobacter cronae sp. nov., isolated from human rectal swabs and stool samples. Int J Syst Evol Microbiol. 2020;70(5):2998-3003.

29. Qian C, Du Y, Li H, Wu P, Wang L, Wei Y, Cao H, Yin Z, Zhang Y, Zhu Y, et al. Development of rapid and simple experimental and in silico serotyping systems for Citrobacter. Future Microbiol. 2018;13:1511-22.

30. Petty NK, Bulgin R, Crepin VF, Cerdeno-Tarraga AM, Schroeder GN, Quail MA, Lennard N, Corton C, Barron A, Clark L, et al. The Citrobacter rodentium genome sequence reveals convergent evolution with human pathogenic Escherichia coli. J Bacteriol. 2010;192(2):525-38.

31. Fashae K, Engelmann I, Monecke S, Braun SD, Ehricht R. Molecular characterisation of extended-spectrum ss-lactamase producing Escherichia coli in wild birds and cattle, Ibadan, Nigeria. BMC Vet Res. 2021;17(1):33.

32. Wang X, Kang Q, Zhao J, Liu Z, Ji F, Li J, Yang J, Zhang C, Jia T, Dong G, et al. Characteristics and epidemiology of extended-spectrum betalactamase-producing multidrug-resistant Klebsiella pneumoniae from Red Kangaroo, China. Front Microbiol. 2020;11:560474.

33. O'Hagan MJH, Pascual-Linaza AV, Couzens C, Holmes C, Bell C, Spence N, Huey RJ, Murphy JA, Devaney R, Lahuerta-Marin A. Estimation of the prevalence of antimicrobial resistance in Badgers (Meles meles) and Foxes (Vulpes vulpes) in Northern Ireland. Front Microbiol. 2021;12:596891.

34. Peter S, Bosio M, Gross C, Bezdan D, Gutierrez J, Oberhettinger P, Liese J, Vogel W, Dorfel D, Berger L, et al. Tracking of antibiotic resistance transfer and rapid plasmid evolution in a hospital setting by nanopore sequencing. mSphere. 2020;5(4):e00525-20.

35. Hu X, Xu H, Shang Y, Guo L, Song L, Zhang H, Yue F, Jiang H, Zheng B. First genome sequence of a blaKPC-2-carrying Citrobacter koseri isolate collected from a patient with diarrhoea. J Glob Antimicrob Resist. 2018;15:166-8.

36. Gelbicova T, Barakova A, Florianova M, Jamborova I, Zelendova M Pospisilova L, Kolackova I, Karpiskova R. Dissemination and comparison of genetic determinants of mcr-mediated colistin resistance in Enterobacteriaceae via retailed raw meat products. Front Microbiol. 2019;10:2824.
37. Nadimpalli M, Fabre L, Yith V, Sem N, Gouali M, Delarocque-Astagneau E, Sreng N, Le Hello S, Group Bs. CTX-M-55-type ESBL-producing Salmonella enterica are emerging among retail meats in Phnom Penh, Cambodia. J Antimicrob Chemother. 2019;74(2):342-8.

38. Seenama C, Thamlikitkul V, Ratthawongjirakul P. Multilocus sequence typing and bla ESBL characterization of extended-spectrum beta-lactamaseproducing Escherichia coli isolated from healthy humans and swine in Northern Thailand. Infect Drug Resist. 2019;12:2201-14.

39. Lupo A, Saras E, Madec JY, Haenni M. Emergence of blaCTX-M-55 associated with fosA, rmtB and mcr gene variants in Escherichia coli from various animal species in France. J Antimicrob Chemother. 2018;73(4):867-72.

40. Ovejero CM, Delgado-Blas JF, Calero-Caceres W, Muniesa M, GonzalezZorn B. Spread of mcr-1-carrying Enterobacteriaceae in sewage water from Spain. J Antimicrob Chemother. 2017;72(4):1050-3.

41. Pilar AVC, Petronella N, Dussault FM, Verster AJ, Bekal S, Levesque RC, Goodridge L, Tamber S. Similar yet different: phylogenomic analysis to delineate Salmonella and Citrobacter species boundaries. BMC Genomics. 2020;21(1):377.

42. Zerbino DR, Birney E. Velvet: algorithms for de novo short read assembly using de Bruijn graphs. Genome Res. 2008;18(5):821-9.

43. Zankari E, Hasman H, Cosentino S, Vestergaard M, Rasmussen S, Lund O, Aarestrup FM, Larsen MV. Identification of acquired antimicrobial resistance genes. J Antimicrob Chemother. 2012;67(11):2640-4.

44. Seemann T. Prokka: rapid prokaryotic genome annotation. Bioinformatics. 2014;30(14):2068-9.

45. Overbeek R, Olson R, Pusch GD, Olsen GJ, Davis JJ, Disz T, Edwards RA, Gerdes S, Parrello B, Shukla M, et al. The SEED and the Rapid Annotation of microbial genomes using Subsystems Technology (RAST). Nucleic Acids Res. 2014;42(Database issue):D206-214.

46. Sitto F, Battistuzzi FU. Estimating pangenomes with roary. Mol Biol Evol. 2020;37(3):933-9.

\section{Publisher's Note}

Springer Nature remains neutral with regard to jurisdictional claims in published maps and institutional affiliations.
Ready to submit your research? Choose BMC and benefit from:

- fast, convenient online submission

- thorough peer review by experienced researchers in your field

- rapid publication on acceptance

- support for research data, including large and complex data types

- gold Open Access which fosters wider collaboration and increased citations

- maximum visibility for your research: over 100M website views per year

At BMC, research is always in progress.

Learn more biomedcentral.com/submissions 